lowland sites are available, especially in the east of the UK, but they will require advanced designs of machine the environmental acceptability of which remains to be established. The offshore resource is likely to be very large indeed, but a questionmark must remain over its economics; things are always more expensive to achieve offshore than on land. So, while wind power is tempting enough to persuade the UK Electricity Boards to buy and try out machines, it cannot yet be regarded as proved.

Wave power is probably the least attractive of the major renewable technologies, though this is not what the author admits. The problem is that one has to have huge devices, moored or otherwise fixed in seas that are among the wildest in the world, with power being transmitted through cables on the sea bed to the mainland shore, and then across hundreds of kilometres on land in order to reach the industrial centres where the power could be used. Such features are costly. And even for island use, it is not clear that wave power will be preferable to wind power, because most islands are windy. The author comes to the neutral conclusion that while there may be a potential for costs to be increased or reduced in the future, "wave power remains an interesting insurance technology which ... needs to be further studied"; this is Establishment code for the fact that, for the UK market at least, commercial prospects do not look good.

The chapter on tidal power is largely a shortened version of the report of the Severn Barrage Committee, which concluded that up to seven gigawatts of electricity should be economically available through a barrage across the Severn Estuary in south-west England. Beyond this, there is a good summary of schemes elsewhere in the world, especially in France and Canada.

Geothermal energy from large underground steam fields is used to generate electricity economically, but this is not a practicable source for most European countries. However, there is a good introduction to world-wide use of the technology, including the use of warm water aquifers which are now being exploited in Europe for space heating. A much more widely distributed form of underground heat lies in impermeable rock, the so-called "hot dry rock" technology. In some places, for example Cornwall and Northumberland in the UK, underground rock structures have especially high temperatures so that more than $200^{\circ} \mathrm{C}$ can be reached at depths of 5-7 km. If one could fracture the rock at such depths and pass water over it, steam could be raised to generate electricity. There is an excellent introduction to this promising new technology, though it is made clear that it is one for the next century. Finally, the book deals with various ways to raise electricity from solar energy including photovoltaic conversion, satellite stations and solar focusing of the Sun's heat.

Alternative Energy Sources is a wellstructured compendium of recent work on the renewables, with especial reference to the UK programme. It is rather uncritical and contains no new insights. Nevertheless, the book represents a useful introduction to the subject, though some scientific education will be required to understand all of the explanations.

F.J.P. Clarke is Director of Management Studies at the United Kingdom Atomic Energy Authority. From 1977 to 1981 he was Chairman of the UK national committees on wind, wave and solar energies.

\section{Alluvial puzzles}

\section{Alayne Street-Perrott}

\section{A Land Between Two Niles: Quaternary Geology and Biology of the Central} Sudan.

Edited by Martin A.J. Williams and D.A. Adamson.

A.A. Balkema, Rotterdam: 1983. Pp.256. Dfl.65, £14.55, \$25.

LEONARDO da Vinci speculated that the Nile floods originated in the Mountains of the Moon. Despite all the detailed work carried out subsequently on the alluvial sequence of the Nile, its Late Quaternary history is still surrounded by controversy. On the one hand, palaeoecologists working in the Nile headwaters insist that the last glacial maximum was cool and dry; on the other, painstaking stratigraphic studies in Nubia and Egypt seem to lead inescapably to the conclusion that the Late Pleistocene Nile was more vigorous and competent than today.

A Land Between Two Niles attempts to resolve these contradictions. It is an interdisciplinary study of the Gezira, which occupies a key position at the confluence of the Blue and White Niles. The Gezira is a complex alluvial fan, consisting mainly of sediments brought down by the Blue Nile from the Ethiopian Highlands. These interfinger with dune sands and with the deposits of the White Nile.

The book begins with brief surveys of the problems of irrigation agriculture in semiarid climates, and of Quaternary environments in Northern Africa. A reconstruction of Late Quaternary vegetation changes in the Sudan is followed by six chapters dealing with the geology, hydrology, landforms, vegetation, soils and stratigraphy of the Gezira. The book concludes with a conceptual model of the fluvial dynamics of the Nile since $20,000 \mathrm{yr}$ BP. At present, the Blue Nile contributes $68 \%$ of the flood discharge of the Main Nile and $72 \%$ of its sediment load. In contrast, the White Nile, which rises in the lakes and swamps of Equatorial Africa, serves mainly to maintain the low-season flow. An important conclusion of this book is that the water and sediment discharge of the Blue Nile have been the overriding influence on the behaviour of the Main Nile throughout the late Quaternary. By taking sediment production as well as climatic change into account, the authors explain many of the puzzling features of the alluvial record.

The Gezira is a region of great economic importance, since it accounts for $65 \%$ of the export revenue of the Sudan and around a fifth of the world's production of long-staple cotton. The authors argue that future development must be based on an understanding of the extent to which the alluvial soils and groundwater reserves are out of phase with present conditions. In this sense, "the past is . . a very real key to the present"

Not surprisingly in a work of this kind, there are occasional disagreements between contributors. More irritating to the reader are the inconsistencies between some of the maps and diagrams, which are made worse by poor reproduction in some cases. Because of the general spatial and systematic organization of the book, it

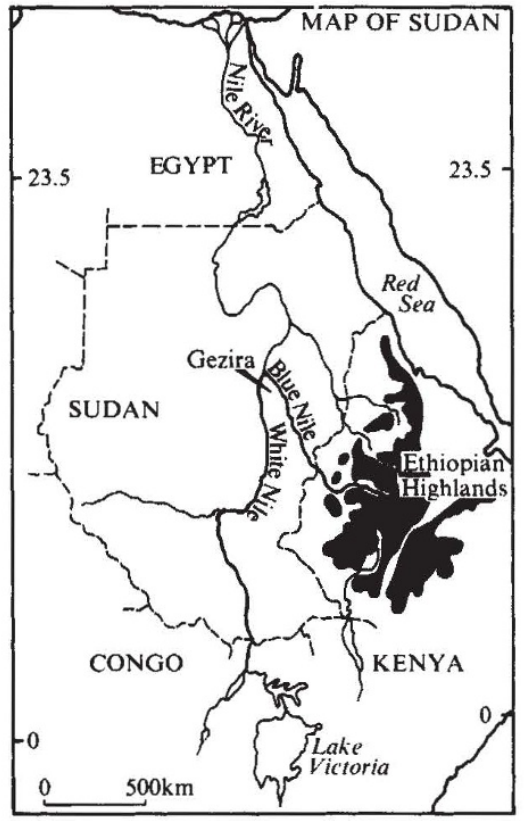

alternates between the present and the Late Pleistocene in a way which leaves the reader slightly queasy.

Nonetheless this volume is a succinct and useful summary of existing information on the past and present landscape of the Gezira. It forms a valuable companion to the earlier work The Sahara and the Nile (edited by M.A.J. Williams and H. Faure, and published by Balkema in 1980), and issues a clear warning to all those Quaternary scientists who would like to infer palaeoclimate from the sedimentary record of large river systems.

Alayne Street-Perrott is a member of the Tropical Palaeoenvironments Research Group at the School of Geography, University of Oxford. 